\title{
PRÉ-NATAL: EXPERIÊNCIAS VIVENCIADAS PELO PAI
}

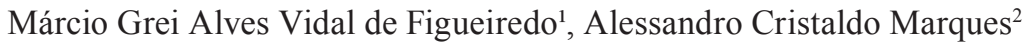

RESUMO: Estudo descritivo-exploratório teve por objetivo identificar as experiências vivenciadas pelo pai ao acompanhar a consulta pré-natal, conhecendo seu perfil socioeconômico, utilizando entrevista semi-estruturada, analisada pela técnica do Discurso do Sujeito Coletivo. A amostra foi composta por 10 pais acompanhantes e os resultados que emergiram em Ideias Centrais: experiências em acompanhar; motivos para participar; como foi acompanhar; contribuições; facilidades e dificuldades para participar. Ressaltou-se o sentimento paterno por estar envolvido na gestação, tornando-se mais atento e preocupado com a saúde da gestante e do bebê. A pesquisa contempla a Política Nacional de Atenção Integral à Saúde do Homem que visa incluir o homem em questões concernentes à saúde reprodutiva.

PALAVRAS-CHAVE: Paternidade; Cuidado pré-natal; Cuidados de enfermagem.

\section{FATHERS' PRE-NATAL EXPERIENCES}

ABSTRACT: A descriptive-exploratory study which aimed to identify the fathers' experiences during the pre-natal consultation process, learning about their socio-economic profile via semi-structured interviews, and analysed through Discourse of the Collective Subject. The sample was composed of ten fathers accompanying the mothers, and the results that emerged were separated into central ideas: the experiences of accompanying: motives for participating: what it is like to accompany: contributions: and what is easy and what is difficult about accompanying. Paternal sentiments are emphasized by becoming involved in pregnancy, making the fathers more attentive and concerned with the health of the mother-to-be and the baby. The research considers the Brazilian National Policy on Integral Health for Men, which aims to include men in matters concerning reproductive health.

KEYWORDS: Paternity; Pre-Natal care; Nursing care.

\section{PRENATAL: EXPERIENCIAS VIVIDAS POR EL PADRE}

RESUMEN: Estudio descriptivo y exploratorio cuyo objetivo fue identificar las experiencias de un padre al acompañar la consulta prenatal, conociendo su perfil socioeconómico, utilizando entrevista semiestructurada, analizada por la técnica del Discurso del Sujeto Colectivo. La muestra fue compuesta de 10 padres acompañantes y los resultados integran las siguientes Ideas Centrales: experiencias en acompañar; motivos para participar; cómo fue acompañar; contribuciones; facilidades y dificultades para participar. Se ha destacado el sentimiento paterno por participar en la gestación, tornándose más atento e involucrándose más con la salud de la gestante y del bebé. La investigación contempla la Política Nacional de Atención Integral a la Salud del Hombre que tiene el propósito de incluir el hombre en cuestiones acerca de la salud reproductiva.

PALABRAS-CLAVE: Paternidad; Cuidado prenatal; Cuidados de enfermería.

${ }^{1}$ Enfermeiro. Especializando em Gestão e Qualificação do SUS e em Atenção Básica em Saúde da Família. Professor do Centro Universitário da Grande Dourados - UNIGRAN.

${ }^{2}$ Enfermeiro. Especializando em Atenção Básica em Saúde da Família. Agente Comunitário de Saúde da Secretaria Municipal de Dourados-MS.

Autor correspondente:

Alessandro Cristaldo Marques.

Centro Universitário da Grande Dourados

Rua Eulália Pires, 3135 - 79823-020 - Dourados-MS-Brasil

E-mail: alessandromarques_dourados@yahoo.com.br
Recebido: 25/05/2011

Aprovado: 05/11/2011

Cogitare Enferm. 2011 Out/Dez; 16(4):708-13 


\section{INTRODUÇÃO}

A gestação é um acontecimento especial, não só para a mulher, mas para o contexto social e cultural que irá influenciar na evolução da gravidez ${ }^{(1)}$. Há uma tendência de o núcleo familiar sofrer transições, no qual a mãe e o pai terão despertados sentimentos para o exercício dos papeis, maternos e paternos, e que surgem de acordo com as mudanças no corpo da mulher, assim como no ambiente em que se constrói o processo de gestação ${ }^{(2)}$.

As mudanças nos sentimentos, assim como as físicas e sociais despertam, por vezes, ansiedade e estresse no meio familiar, e também individual, exigindo do enfermeiro precisa observação e análise deste contexto durante a consulta de enfermagem a fim de prestar assistência pré-natal de qualidade, considerando uma família grávida, preparando-a para o parto e pós-parto saudável e seguro ${ }^{(3)}$. Neste contexto, a inserção do homem na consulta de prénatal pode contribuir para o binômio de relacionamento entre pai-filho. Portanto, os profissionais devem incentivar o acompanhamento do pai e o envolvimento deste no processo gravídico. $\mathrm{O}$ enfermeiro como integrante da equipe de saúde e um dos responsáveis pela realização do pré-natal na rede básica de saúde deve proporcionar o acolhimento do pai na unidade para que possa integrarse no processo gestacional ${ }^{(4)}$. É fundamental garantir ao pai o direito de acompanhar a gestante nas consultas, incluindo-o em grupos de gestantes ou de casais grávidos para prepará-lo às especificidades da paternidade ${ }^{(5)}$, considerando que a gestação é um período de preparação para assumir novos papeis ${ }^{(6)}$.

Observa-se transformações no tocante à paternidade durante o período gravídico, não sendo este, mais um universo exclusivamente feminino ${ }^{(6)}$, agora desencadeado por um paradigma de progressão entre as fronteiras de maternidade e paternidade ${ }^{(7)}$. Nessa perspectiva, a inclusão do homem na saúde reprodutiva, objetiva, entre várias propostas, proporcionar a constituição da igualdade de gêneros ${ }^{(8)}$. Nesse sentido, o Ministério da Saúde divulgou em 2008 a Política Nacional de Atenção Integral à Saúde do Homem, voltada exclusivamente à saúde masculina. Esta política tem, entre outros objetivos, o de promover e desenvolver ações que contribuam na compreensão da singularidade masculina em seu contexto real, sociocultural e político-econômico e assim possibilitar a adoção de medidas e estratégias para o acesso aos serviços para a prevenção e promoção da saúde, bem como nortear futuras intervenções. E, nesta política, estão contemplados os direitos sexuais e reprodutivos, onde incentiva-se a conscientização masculina sobre os direitos e deveres do homem na participação do planejamento reprodutivo, assim considerando que:

A paternidade não deve ser vista apenas do ponto de vista da obrigação legal, mas, sobretudo, como um direito do homem a participar de todo o processo, desde a decisão de ter ou não filhos, como e quando tê-los, bem como do acompanhamento da gravidez, do parto, do pós-parto e da educação da criança ${ }^{(9: 16)}$.

A presente política enfatiza a necessidade de mudanças de paradigmas no que concerne à percepção da população masculina em relação ao cuidado com a sua saúde e a saúde de sua família"(9:28),

cabendo ao sistema público e aos profissionais implantar e desenvolver de acordo com essa política, seus princípios e diretrizes.

Deste modo, esta pesquisa teve por objetivo identificar as experiências vivenciadas pelo pai ao acompanhar a consulta pré-natal, conhecendo seus motivos, contribuições, facilidades e dificuldades ao acompanhar a gestante, assim como perceber seu perfil socioeconômico.

\section{MÉTODO}

Trata-se de uma pesquisa com abordagem quantiqualitativa, descritiva e exploratória, realizada em Unidade Básica de Saúde (UBS), em Dourados- Mato Grosso. A pesquisa foi realizada com os homens, acompanhantes de suas parceiras, na consulta de prénatal; foram critérios de inclusão: ter acompanhado pelo menos uma consulta do pré-natal e com idade superior a 18 anos. Todos os participantes assinaram o Termo de Consentimento Livre e Esclarecido, observando-se preceitos éticos em pesquisas envolvendo seres humanos.

Foram obtidos da gerência da unidade os dias e horários em que eram realizadas as consultas do prénatal, sendo os dados coletados entre agosto a setembro de 2010. Após a abordagem dos acompanhantes e tendo aceito participar, a entrevista semiestruturada foi realizada na unidade ou, se da preferência do participante, em outro dia, local e horário previamente agendado. As entrevistas obedeceram um roteiro baseado no instrumento de coleta utilizado por Cavalcante ${ }^{(10)}$, foram gravadas, transcritas na íntegra e analisadas com base na técnica do Discurso do Sujeito Coletivo (DSC). O DSC utiliza as Expressões-Chave (ECH) semelhantes da narrativa de cada sujeito acerca de uma Idéia Central (IC), construindo um novo discurso na primeira pessoa do singular falando pelo coletivo, 
na forma de um "eu", mas envolvendo as opiniões de todos da pesquisa. Essas ECH são trechos retirados dos discursos de cada sujeito e as IC uma forma de sintetizar, agrupando esses discursos para transmitir a proposta de uma forma clara ${ }^{(11)}$.

O projeto de pesquisa foi aprovado, sob o protocolo n. 132/10, pelo Comitê de Ética em Pesquisa do Centro Universitário da Grande Dourados, respeitando a Resolução n. 196/96 do Conselho Nacional de Saúde que dispõe das normas e diretrizes regulamentadoras para pesquisas em seres humanos.

\section{RESULTADOS}

A amostra constituiu-se por 10 pais e cujo perfil socioeconômico está apresentado na Tabela 1.

\section{Apresentação dos DSC}

Emergiram seis Discursos do Sujeito Coletivo, obtidos a partir das entrevistas, e apresentados a seguir.

\section{Idéia Central: Experiências em acompanhar a consulta}

Ah, é gostoso quando a gente vai e fala dele [...] você tem um fruto seu ali, não é?[...]. É gratificante a gente ir lá, esclarecer nossas dúvidas, perguntar certinho o que tá acontecendo com o nenê, escutar os batimentos cardíacos.[..] A médica pega e esclarece tudinho como a criança se forma lá dentro da barriga da mãe. Eu fiquei sabendo que tá desenvolvendo. Foi uma experiência nova, diferente, só que eu achei muito importante tá participando, tá acompanhando, porque a gente fica tanto mais próximo da criança, quanto da mulher. $\dot{E}$ muito importante para o pai a oportunidade de chegar, poder apoiar, estar junto com a esposa no consultório médico. A gente fica com medo, mas a experiência é boa. Se você não vai com sua esposa, você não sabe o quê acontece. É a emoção de estar lá perto, não é. (DSC 01)

\section{Idéia Central: Os motivos para participar}

O primeiro motivo é que eu gosto muito da minha esposa e da criança que tá gerando dentro dela; e para compartilhar aquele momento com ela, pois não é uma consulta normal, então é tanto bom pra mim quanto prá minha mulher. Quero estar sempre ciente do que tá acontecendo na gravidez, quero sempre estar presente, acompanhar o bebê, se ele está bem ou ela mesmo, não é. Curiosidade também prá tá mais por dentro do assunto. Ela tem dúvida, eu também tenho, saber se tá tudo bem, se tem algum risco com ela, saber cuidar da gestante e do bebê não é. E apoio, um apoio familiar, estar junto dela eu acho que é importante o cara tá junto, não é. O pai da criança, a mulher se sente mais

Tabela 1 - Perfil socioeconômico dos pais que acompanharam consultas de pré-natal. Dourados, 2010

\begin{tabular}{|c|c|c|c|c|c|c|}
\hline ENTREVISTADO & $\begin{array}{l}\text { IDADE } \\
\text { (ANOS) }\end{array}$ & $\begin{array}{l}\text { ESTADO } \\
\text { CIVIL }\end{array}$ & ESCOLARIDADE & PROFISSÃO & $\begin{array}{l}\text { RENDA } \\
\text { MENSAL(R\$) }\end{array}$ & $\begin{array}{l}\text { HORÁRIO DE } \\
\text { TRABALHO }\end{array}$ \\
\hline E1 & 23 & Solteiro & Ensino Médio Incompleto & $\begin{array}{l}\text { Operador de Má- } \\
\text { quinas }\end{array}$ & $1.232,00$ & $08: 00 \mathrm{~h}$ às $16: 00 \mathrm{~h}$. \\
\hline E2 & 22 & Casado & Ensino Médio & Promotor de Vendas & 600,00 & $\begin{array}{l}07: 00 \mathrm{~h} \text { às } 11: 00 \mathrm{~h} \\
13: 00 \mathrm{~h} \text { às } 17: 00\end{array}$ \\
\hline E3 & 20 & Casado & Ensino Médio & Vendedor & 800,00 & $\begin{array}{l}07: 00 \mathrm{~h} \text { às } 11: 00 \mathrm{~h} \\
13: 00 \mathrm{~h} \text { às } 17: 00\end{array}$ \\
\hline E4 & 28 & Solteiro & Ensino Médio & Salgadeiro & 700,00 & $\begin{array}{l}07: 00 \mathrm{~h} \text { às } 11: 00 \mathrm{~h} \\
13: 00 \mathrm{~h} \text { às } 17: 00\end{array}$ \\
\hline E5 & 44 & Casado & Ensino Fundamental Incompleto & Pedreiro & 800,00 & $\begin{array}{l}07: 00 \mathrm{~h} \text { às } 11: 00 \mathrm{~h} \\
13: 00 \mathrm{~h} \text { às } 17: 00\end{array}$ \\
\hline E6 & 42 & Casado & Ensino Fundamental & Motorista & $1.800,00$ & 21:00h às 05:00h \\
\hline E7 & 27 & Solteiro & Ensino Fundamental Incompleto & Motorista & $1.100,00$ & $18: 40 \mathrm{~h}$ às $09: 00 \mathrm{~h}$ \\
\hline E8 & 31 & Solteiro & Ensino Médio & Servente de Pedreiro & 800,00 & $\begin{array}{l}07: 00 \mathrm{~h} \text { às } 11: 00 \mathrm{~h} \\
13: 00 \mathrm{~h} \text { às } 17: 00\end{array}$ \\
\hline E9 & 23 & Solteiro & Ensino Fundamental & Auxiliar de Produção & 510,00 & $14: 30 \mathrm{~h}$ às $23: 30 \mathrm{~h}$ \\
\hline E10 & 32 & Casado & Ensino Fundamental Incompleto & Servente Industrial & 650,00 & $04: 00 \mathrm{~h}$ às $16: 00 \mathrm{~h}$ \\
\hline
\end{tabular}


segura por que ela sabe que tem um companheiro ali, porque, na verdade, você tem uma esposa, você vai ter uma família e é responsabilidade dos dois. (DSC 02)

\section{Idéia Central: Como foi acompanhar}

Foi legal, gostoso heim, pra mim foi bom, foi excelente. Cara, é gostoso tá falando sobre o bebê, escutar o barutho do coraçãozinho batendo (tá, tá, tá...), sabendo que alguns meses vai tá no meu braço aqu. Para mim, é gratificante, é o maior prazer do mundo. Eu me senti alegre, feliz de estar acompanhando ela, foi emocionante![...] $E$ eu estou indo porque eu quero mesmo, porque eu gosto de acompanhar ela e acho que o casal fica mais unido. Eu acho muito bom, pra mim tá sendo bom mesmo estar por dentro do que tá acontecendo. (DSC 03)

\section{Idéia Central: Contribuições na gestação}

Olha, fazendo o possivel prá o que ela precisa. Acompanho todo passo da gravidez dela, marco as consultas, procuro ser mais paciente, mais tolerante, procuro sempre estar perto, estar sempre conversando, apoiando, tá sempre disposto a ajudar, não é. A hora que ela precisa mais, a hora que tá nervosa, vou, tento controlar ela, acalmar ela, prá não prejudicar o nenê, porque ela fica naquela expectativa, ansiedade não é, fica meio nervosa. Acho que do esposo tá junto já chega ser uma contribuição, deixa ela mais aliviada e mais tipo confiante não é, tendo sempre alguém prá dar apoio ali. A gente sente que ela fica mais tranquila com você do lado. Bom, no que for preciso eu contribuo, estou em casa, limpo, dou uma ajeitada nas coisas, lavo louça, ajudo na alimentação. [...] É cara, eu acho que fiz a minha parte em tudo que ela precisou, tá sempre o máximo que a gente pode do lado dela e dar carinho que é necessário não é. (DSC 04)

\section{Idéia Central: Facilidades para participar}

[...] é dificil, mas a gente vai, sempre eu dou um jeito, não é. Oatendimento émuito rápido pormais que ela chegue super atrasada, ou chegue sem ter marcado consulta.[...]Ela tem preferência, Então, a gente chega, passa alguns minutos, já atende já. Prá mim, é tranquilo participar, eu acho normal o homem tá acompanhando as consultas. (DSC 05).

\section{Idéia Central: Dificuldades para participar}

A maior dificuldade hoje é o meu serviço [...]. Eu tenho que conversar com o meu supervisor, prá me liberar mais cedo, prá eu poder levar ela. Você sai do seu serviço cansado, às vezes você tem um compromisso prá fazer, você deixa de fazer para estar lá, mas é minha familia que tá em jogo, não é.[...] Penso nela primeiro. Por causa do horário, tinha vez que eu não podia estar indo, é cedo, tem que levantar prá marcar e dai eu não estou presente, tanto na hora de ir como na consulta [...]. No horário que eu saio ela tem que ir, e na hora que eu volto já tá acabando a consulta. Não bate, não dá certo e o posto é um pouco longe, a gente tem dificuldade pra ir, condução, essas coisas e às vezes tem que deixar as outras crianças com outras pessoas. Dificuldade também é tá entendendo tudo não é, tá acompanhando passo a passo é um pouco complicad, tem que tá sabendo, mas tá tudo bem. (DSC 06)

\section{DISCUSSÃO}

A faixa etária dos pais variou de 20 a 44 anos, com média de 29 anos, semelhante a outros estudos ${ }^{(4,6,12)}$. Todos os participantes residiam com as gestantes, sendo que $50 \%$ eram casados e os demais união consensual; semelhante ao identificado em outras pesquisas ${ }^{(4,6)}$.

Quanto à escolaridade observou-se que nenhum pai possuía curso superior, diferentemente de pesquisa onde cerca de $40 \%$ cursavam ou haviam concluído curso de graduaçao ${ }^{(6)}$. Profissões semelhantes foram encontras em outras pesquisas como as de pedreiro, servente de pedreiro, motorista, ajudante de cozinha, borracheiro, encarregado de produção e outras ${ }^{(4,12)}$. Quanto ao horário de trabalho percebeu-se que a maioria dos pais trabalha nos horários mais comuns de realização do pré-natal -manhã e tarde- tornandose a principal dificuldade no acompanhamento das consultas, semelhante a outras pesquisas ${ }^{(4,10,13)}$.

\section{Análise dos discursos}

Notou-se que o pai carrega muitas dúvidas acerca da gestação e o desenvolvimento do bebê e sabe que, ao participar do pré-natal, tem a oportunidade de perguntar e saná-las. Ficou evidente a emoção vivida em acompanhar a gestante nas consultas, embora seja diferente e tudo muito novo; apenas o fato de poder participar já o torna grato, principalmente ao saber que tudo está ocorrendo naturalmente (DSC 01). Nessa perspectiva, o pai sente-se privilegiado participando da consulta ${ }^{(10)}$. Por vezes o pai, frente às dúvidas, faz acordos com a companheira, afim de esclarecê-las durante as consultas; considera relevante acompanhar 
os movimentos, o desenvolvimento e o crescimento do bebê $\hat{e}^{(13)}$.

Percebeu-se o envolvimento do pai durante a gravidez, contrastando com estudo sobre cursos de orientações pré-natal ${ }^{(7)}$. Um motivo significativo que leva um homem que será pai, a acompanhar e participar com sua esposa ou companheira o pré-natal é o compromisso com a mãe e com o futuro bebê. Mas, além disso, o futuro pai tem consciência da sua parcela de responsabilidade e contribuição no acompanhamento da gestação. Logo, a preocupação com a gestante e o bebê possibilita uma aproximação para as mudanças, para compreender o desenvolvimento gestacional, sentindo prazer e demonstrando preocupação com a gestante, com o bebê e com a evolução da gestação. $\mathrm{O}$ pai chama para si a responsabilidade em acompanhá-la durante esse período, pois estão juntos na espera do filho; sendo assim, faz-se mais presente e próximo da mulher, a considera em estado mais frágil, despendendo de maior energia, necessitando de cuidados consigo e com o bebê $\hat{e}^{(10)}$.

Em estudo sobre o envolvimento paterno na gestação, os pais referiram preocupação com a saúde da gestante, seu bem estar e restrições decorrentes da gestação, consideraram a necessidade de maior apoio afetivo e material, além da preocupação com a saúde do bebê $\hat{~}^{(6)}$. Essa preocupação está relacionada com sua saúde, livre de qualquer má formação ${ }^{(13,14)}$.

A satisfação vivenciada pelo pai ao participar da consulta proporciona emoção e expectativa frente a chegada do filho; relevante é a afirmação quanto a sua decisão em participar das consultas, enfatizando a união do casal como grande conquista da gravidez (DSC 03).

O pai sente-se recompensado em assistir e acompanhar as consultas pré-natais ${ }^{(10)}$ e envolvido com a gravidez $^{(13)}$. Emoção sentida ao ouvir os batimentos do coração ${ }^{(12)}$, sendo este um desejo unânime dos pais e que representa a materialização do bebê, percebida antes, apenas por informações advindas da mãe ${ }^{(8)}$.

A escuta dos batimentos do coração do bebê, pode contribuir para a aproximação do casal, de acordo com estudos que referiram melhor relação, união e fortalecimento do casal durante a gestação ${ }^{(13-14)}$.

Para o homem, o fato de acompanhar e compartilhar esse momento da consulta se constitui em contribuição; de acordo com a sua percepção cria-se um leque de atitudes que tornam-se contribuições, desde a realização de serviços domésticos ao carinho ofertado. O pai preocupa-se muito com o estado emocional de sua companheira, tentando mante-la calma e tranquila, pois sente que sua presença a deixa mais aliviada e confiante (DSC 04). Estudo acerca do envolvimento paterno ressalta a importância do apoio emocional, incluindo verbalizações concernentes a acalmar a companheira, tranquilizá-la, elogiar as transformações em seu corpo, ter maior disponibilidade, dialogar, ser pacífico e compreensivo; o apoio material, como auxílio nos afazeres domésticos, também é valorizado ${ }^{(6,14)}$.

A gestação é um período de grande ansiedade do casal, e como uma forma sublime de contribuição, o pai posiciona-se sendo continente e carinhoso, oferecendo um apoio incondicional à gestante/esposa ${ }^{(13)}$. $\mathrm{O}$ homem, sempre que possível, acompanha a gestante até a unidade de saúde; embora o atendimento seja preferencial, e por isso, mais rápido para gestantes, nem sempre é possível o acompanhamento contínuo do pai (DSC 05). Estudo revelou que muitos desconhecem o direito do pai em acompanhar a gestante na consulta pré-natal ${ }^{(4)}$, previsto na Lei n. 9.263/96, que trata do planejamento familiar, garantindo à mulher, ao homem e ao casal o atendimento integral à saúde, em todos os ciclos vitais, incluindo na assistência pré-natal ${ }^{(15)} \mathrm{e}$ reiterada pela Política Nacional de Atenção Integral à Saúde do Homem, que incentiva a sua participação em questões concernentes à saúde reprodutiva ${ }^{(9)}$.

No que tange ao atendimento percebeu-se a satisfação com a assistência pré-natal e o serviço público, facilidade no agendamento das consultas, acolhimento participativo e informações, corroborando os resultados de outro estudo ${ }^{(10)}$. Porém, também foi evidente a dificuldade enfrentada pelo pai para participar e acompanhar as consultas do pré-natal, sendo esta o fator trabalho. Ainda assim, o pai reconhece a participação como importante ao referir que é sua família que está jogo, embora esta e outras dificuldades, como ter que cuidar dos demais filhos, acabam impossibilitando sua participação (DSC 06), em sua maioria associada ao horário em que as consultas são realizadas, que coincide com o horário de trabalho. Estudo revelou que pedir dispensa do trabalho para acompanhar a gestante, embora previsto em lei, pode ser um motivo para demissão ${ }^{(10)}$. Contudo, a falta de interesse e de tempo também foram motivos identificados ${ }^{(4)}$, assim como o fato de não serem convidados ${ }^{(4,8)}$.

Outra dificuldade identificada foi o desafio de compreender o que está se passando com a gestante e as necessidades advindas da gravidez. Há por parte do pai a preocupação em entender o processo gestacional, eles relatam inexperiência, referindo-se às habilidades 
indispensáveis nos cuidados com o filho, que também deveriam ser transmitidas ao pai $^{(6)}$.

\section{CONSIDERAÇÕES FINAIS}

Conclui-se que, sob a visão dos pais, sua participação nas consultas pré-natal contribui com o processo gestacional e com a união do casal e permite conhecer melhor as mudanças ocorridas com a gestante, sendo uma oportunidade para obter informações e minimizar a insegurança e ansiedade decorrente das dúvidas, expectativas e dos cuidados com o filho. A pesquisa vem ao encontro do cenário nacional das políticas públicas, pois com a divulgação da Política Nacional de Atenção Integral à Saúde do Homem espera-se a realização de pesquisas voltadas à saúde masculina, e a inclusão na saúde reprodutiva é um dos grandes objetivos dessa política. Para os profissionais envolvidos nessa prática, com destaque ao enfermeiro, os resultados constituem incentivo à inclusão paterna na assistência pré-natal.

\section{REFERÊNCIAS}

1. Tsunechiro MA, Bonadio IC. A família na rede de apoio da gestante. Fam Saúde Desenvolv. [Internet] 1999;1(1/2) [acesso em 9 nov 2009]. Disponível: http://ojs.c3sl.ufpr.br/ojs2/index.php/refased/article/ viewFile/4853/3717

2. Dessen MA, Braz MP. Rede social de apoio durante as transições familiares decorrentes do nascimento dos filhos. Psicol. 2000;3(16):221-31.

3. Freitas F. Rotinas em obstetrícia. $4^{\mathrm{a}}$ ed. Porto Alegre: Artmed; 2001.

4. Oliveira SC, Ferreira JG, Silva PMP, Ferreira JM, Seabra RA, Fernando VCN. A participação do homem/ pai no acompanhamento da assistência pré-natal. Cogitare Enferm. [Internet] 2009;4(1) [acesso em 01 nov 2009]. Disponível: http://ojs.c3sl.ufpr.br/ojs2/index. php/cogitare/article/view/14118/9489

5. Carvalho MLM. Participação dos pais no nascimento em maternidade pública: dificuldades institucionais e motivações dos casais. Cad Saúde Pública. [Internet] 2003;19(2) [acesso em 9 nov 2009]. Disponível: http:// www.scielosp.org/pdf/csp/v19s2/a20v19s2.pdf

6. Piccinini CA, Silva MR, Gonçalves TR, Lopes RS. O envolvimento paterno durante a gestação. Psicol: Reflex Crít. [Internet] 2004;17(3) [acesso em 15 nov
2009]. Disponível: http://www.scielo.br/pdf/prc/v17n3/ a03v17n3.pdf

7. Nakano MAS, Shimom AKK. Espaço destinado ao homem nos cursos de orientação pré-natal. Feminino. 1995;23(7):657-60.

8. Siqueira MJT, Mendes D, Finkler I, Guedes T, Gonçalves MDS. Profissionais e usuárias (os) adolescentes de quatro programas públicos de atendimento pré-natal da região da grande Florianópolis: onde está o pai? Estud Psicol. 2002;7(1):65-72.

9. Ministério da Saúde. Política Nacional de Atenção Integral á Saúde do Homem. Brasília: Ministério da Saúde; 2008.

10. Cavalcante MAA. A experiência do homem como acompanhante no cuidado pré-natal [tese]. São Paulo: Universidade de São Paulo; 2007.

11. Lefreve F, Lefreve AMC. O discurso do sujeito coletivo: um novo enfoque em pesquisa qualitativa (desdobramentos). Caxias do Sul: EDUCS; 2003.

12. Gonçalves SD, Parada CMGL, Bertoncello NMF. Percepção de mães adolescentes acerca da participação paterna na gravidez, nascimento e criação do filho. Rev Esc Enferm USP. 2001;35(4):406-12.

13. Borholdt EA, Wagner A, Standt ACP. A vivência da gravidez do primeiro filho à luz da perspectiva paterna. Psicol Clin. 2007;19(1):75-92.

14. Krob AD, Piccinini CA, Silva MR. A transição para a paternidade: da gestação ao segundo mês de vida do bebê. Psic USP. 2009;20(2):269-291.

15. Brasil. Lei n. 9.263, de 12 de janeiro de 1996. Regula o $\S 7^{\circ}$ do art. 226 da Constituição Federal, que trata do planejamento familiar, estabelece penalidades e dá outras providências. Diário Oficial da República Federativa do Brasil, Brasília, 15 jan. 1996. Seção: 1. 